\title{
Responsible Gambling Policies and Practices in Macao: A Critical Review
}

\author{
Gui-Hai Huang \\ Gaming Teaching and Research Center, Macao Polytechnic Institute, Macao SAR \\ *Corresponding author; email: ghhuang@ipm.edu.mo
}

\begin{abstract}
Gambling has been a legalized industry in Macao since 1847 and it is now the largest casino city in the world in terms of gross gaming revenue. However, no governmental efforts to control gambling-related harms were made until the Resilience Centre was set up in 2005. Based on a literature review and data gathered from field studies, this paper documents what has been undertaken by government, casino operators, gambling treatment and social service professionals, gambling researchers and academia to promote responsible gambling. Macao's efforts to promote responsible gambling include public awareness for different communities, free treatment services for residents, as well as tourists who seek help, and also research. Although responsible gambling practices are new to Macao, and sound governance on responsible gambling policies has yet to be developed, the Macao government has announced its intention to enforce responsible gambling as an integral part of gaming policies. It is hoped that Macao will further improve responsible gambling practices under the leadership of local government.
\end{abstract}

Key words Macau Casinos · Responsible Gaming $\cdot$ Problem Gambling

\section{Introduction}

Macao has legalized commercial casino gaming since 1847 and achieved renown as the 'Monte Carlo of the Orient' and 'Las Vegas of the East' due to its success in the casino gaming business (Siu, 2006). The Sociedade de Turismo e Diversões de Macao (STDM) held the casino monopoly concession from 1962 until competition was introduced into the industry in 2002. This represented a watershed for Macao's development as an international gambling destination. Three concessions were granted to Sociedade de Jogos de Macau (SJM), a subsidiary of STDM, Galaxy Casino, 
S.A.(Galaxy), and Wynn Resorts Macao S.A. (Wynn) in 2002; no casino other than SJM's operated until May 2004, when Casino Sands of Venetian Macao S.A. (Venetian) opened. The government then allowed each of the three concessionaires to grant a sub-concession. As a result, there are currently six casino operators in Macao, namely SJM, Galaxy, Wynn, Venetian, MGM Grand Paradise, S.A. (MGM), and Melco Crown Gaming (Macau) Ltd. As of May 2011, 34 casinos and 10 slot lounges were operating in Macao. Gaming opportunities are readily accessible to all Macao residents and visitors aged 18 years or above.

The casino gaming industry has experienced an unprecedented expansion since 2002, especially after 2003 when the government of China initiated the individual visitors scheme, easing restrictions on travel by individual mainland Chinese to Macao and Hong Kong. Macao's gross gaming revenue (GGR) was 29\% of that of Nevada and $60 \%$ of that of the Las Vegas Strip in 2002. It exceeded the Las Vegas Strip in 2006 and the whole state of Nevada in 2008. In 2010, its GGR was US\$ 23.5 billion, equivalent to 2.26 times that of Nevada, and 4.06 times that of the Las Vegas Strip (Schwartz, 2011). Such phenomenal expansion has produced enormous economic benefits to casino operators and the Macao government, and has created substantial employment opportunities at casinos and in the catering and service fields. The contribution of gaming taxes to total fiscal revenue increased from $28.1 \%$ in 1999, to 74\% in 2009 (Zeng, 2010, p. 27). Macao's average real economic growth rate is $14.9 \%$ per annum; the unemployment rate dropped from $6.3 \%$ to 2.9\% between 2002 and 2009 (Statistics and Census Service, 2002, 2009).

However, gambling expansion has also caused adverse social and economic consequences, such as problem gambling, bankruptcy, loan sharking and crime. A conservative estimate shows that the financial costs of gambling in Macao increased by 163\% between 2003 and 2007 (Fong et al, 2011). Of note, this estimate took account only of the direct monetary costs of treatment and prevention. Although evidence-based information on the overall economic and social costs of gambling is not available in Macao, there has been concern among the general public about the negative consequences of expanding gambling activities (Sou \& Cheang, 2008).

While the majority of adults enjoy legalized gambling as a recreational activity without any harm, a small percentage of gamblers develop an addiction that compromises, disrupts or damages personal, family or vocational pursuits (Rickwood et al., 2010; Shaffer \& Martin, 2011). Gambling surveys indicate that the number of gamblers affected by problem gambling has been increasing. The first estimate of gambling prevalence conducted in 2003 (Fong \& Ozorio, 2005) showed that $1.78 \%$ of Macao residents aged between 15 and 64 years were probable pathological gamblers and another $2.5 \%$ were probable problem gamblers. A similar survey in 2007 showed an increase in both pathological gambling and problem gambling rates: $2.6 \%$ and $3.41 \%$, respectively (Fong, 2009). No data about problem gambling among tourists are available.

Responsible gambling has been defined by Blaszczynski and colleagues (2004) as being policies and practices designed to prevent and reduce potential harms associated with gambling. These policies and practices often incorporate a broad range of interventions aimed at promoting consumer protection, community/ 
consumer awareness and education, and access to effective treatment. Responsible gambling measures employed in different countries vary considerably. These measures can be categorized as harm minimization and consumer protection strategies (Hing, 2001). Harm minimization strategies are employed to limit possible damages. Examples of harm minimization measures include: pre-commitment and self-exclusion options, restricting access to cash for gambling, limiting cash withdrawals from ATMs signage and publications that provide information on possible indicators of problem gambling, and contact details for treatment services. Consumer protection strategies are those that promote fair trading, informed choice, and protect consumer rights, such as information about the nature of gambling, the chances of winning and losing, and prohibition of misleading advertisement.

Evidence on the effectiveness of these measures is limited and mixed to date (Blaszczynski et al., 2011). Ladouceur et al's (2000) study suggests that self-exclusion programs looks promising. Boutin et al. (2009) reported that providing information could correct misperceptions about randomness but had little impact on behavior. Pre-commitment options have been reported as effective in reducing the incidence of problem gambling (Productivity Commission, 2010).

All key stakeholders including government, gaming operators, treatment professionals, academics and gambling researchers have to work together to make responsible gambling programs successful. Taking the stakeholders' perspective (Freeman, 1984), this paper documents what stakeholders in Macao have achieved with regard to customer protection, harm minimization and research on responsible gambling since 2002. No systematic review or discussion of these inititatives has been reported in the literature previously. Lastly, suggestions for improvements in responsible gambling policies, programs and research in Macao are made.

\section{Method}

In order to provide systematic documentation of responsible gambling policies and practices in Macao, multiple strategies were used. Firstly, a comprehensive literature search was undertaken via electronic databases (e.g. PsycInfo, Medline, ProQuest 5000 International and ScienceDirect) to review relevant publications. This led to the identification of 14 academic papers in English on Macao gambling, and 11 papers in Chinese from three Macao journals (i.e. Journal of Macao Studies, Journal of Macao Polytechnic Institute, and Macao Journal of Public Administration).

Between December 2010 and May 2011, the author visited the main government authorities with responsibilities relating to gambling in Macao (e.g. the Gaming Inspection and Coordination Bureau, abbreviated as DICJ in Portuguese), all the problem gambling counseling centres in Macao (e.g. the Resilience Centre and the Yat On Centre), and other organizations that promote public awareness (e.g. Macao New Chinese Youth Association). These visits sought answers to the following questions:

(1) "What has your organization done with regard to responsible gambling or problem gambling treatment?" and

(2) "What is the challenge for your organization in promoting responsible gambling?"

Each of these visits lasted on average between 1.5 to 2 hours. 
Lastly, data were collected from the websites of all these organizations and the following organizations: the Institute for the Study of Commercial Gaming at the University of Macau, the Gaming and Teaching Research Center at Macao Polytechnic Institute, all the non-governmental organizations (NGOs) in Macao which have problem gambling prevention programs, and all the casino operators. The author's efforts to obtain data directly from casino operators have not been successful to date.

\section{Governmental efforts}

Gaming is the pillar industry in Macao. Gaming tax, which includes a supplementary charge for tourism promotion and social development, is around $40 \%$ of GGR (Huang, 2010a). Casino taxes currently represent around 70\% of government revenue. At the end of 2009, the government had accumulated a fiscal surplus of more than US $\$ 16.8$ billion, which is about twice the level of annual government expenditure (Huang, 2010b). It is in the Macao government's best interests to maintain the long-term sustainability of the gaming industry and to avoid any negative impact of gambling that might impede Macao's development as a major Asian entertainment metropolis. The Macao government also has both the authority and the resources to promote responsible gambling.

However, the government has been slow to take action to promote responsible gambling. Since 1999, reference to the need for proper regulation of the gaming industry has always been made in the Chief Executive's Annual Policy Address. It was not until 2005 that the then Chief Executive, Edmond Ho, referred to the negative impact of excessive gambling, promising that sufficient resource would be employed to reduce the incidence and prevalence of pathological gambling, in order to promote the gaming industry's healthy development (Ho, 2004). Following institution of this new public policy, the Resilience Centre was set up in November 2005 as a division of the Social Welfare Bureau (IAS). Since then, the Resilience Centre has been engaged in extensive work in treatment, prevention, and research concerning problem gambling.

In addition, with the direct involvement of the Resilience Centre, the IAS initiated the Problem Gambling Centralized Registration System in January 2011 to collect data about the characteristics of problem gamblers (e.g. sex, marital status, occupation). The IAS aims to extend the current counseling service to problem gamblers who do not seek help on their own initiative.

The DICJ introduced a voluntary self-exclusion service in 2008. Gamblers or their family members can apply to DICJ which then requests all six casino operators to ban these gamblers once it confirms the application. However, this service has no formal legal authorization. According to the author's visit to DICJ in May 2011, no prosecution has yet been initiated, and data about the number of self-excluders are not available to the general public.

Other government agencies, such as the Education and Youth Bureau and the Tertiary Education Service Office also endeavor to promote responsible gambling by providing information about healthy financial management, and by sponsoring not-for-profit organizations to mount public awareness/education events.

The Macao government is also working to tighten gambling regulations. 
Article 24 of Act No.16/2001 'Casino Games of Fortune Administration Law' bans minors under the age of 18 years from entering a casino. It also bans casino employees from entering their employers' casinos outside work time. The civil servants are not allowed to enter a casino either except during the Chinese New Year public holiday. In order to prevent underage gambling, a draft law 'Restrictions for Access, Stay and Gambling in Casinos' which will increase the minimum age for entry to a casino from 18 to 21 years, is under discussion in the Legislative Assembly. The draft law, for the first time, stipulates that the casino wagers and winnings of anyone under 21 years will be automatically forfeited to the government. It will also formally introduce a self-exclusion program that will incorporate fines of US $\$ 125-1,250$ for self-excluders who enter a casino, forfeiture of their wagers and winnings, and will institute a formal procedure for screening self-excluders.

The Macao government has declared a ceiling on the number of gaming tables of 5500 for 2013, compared to 4791 gaming tables at the end of 2010 (Macao Daily, 2011) The government has also promised to control the number of new casinos and slot machines. Such policy hopefully will encourage casino operators to support responsible gambling

However, a systematic responsible gambling policy remains to be established despite the former Chief Executive's declaration in 2009 that Macao would set up responsible gambling guidelines following international best practice (Ho, 2008). Agreement on what constitutes 'best practice' has not been reached in Macao. The Macao government also faces a conflict between revenue generation from gambling and serious promotion of responsible gambling policy.

\section{Casino operators' efforts}

At the company level, most of Macao's six casino operators have taken some action to help address problem gambling prevention and / or treatment. For example, all operators reported providing responsible gaming training to their staff, and such training has become a regular part of new staff orientation programs. Casino Lisboa displays a Chinese poem warning gamblers about excessive gambling: "We advise you to play merely for pleasure and to risk only what you can spare" (Sun \& Li, 2005). SJM contributed to the establishment and running of the Yat On Centre. The websites of Galaxy and Venetian include information on the symptoms of problem gambling, how to control gambling behavior, where to apply for self-exclusion, where to get treatment, and so on. Such information was not available on the websites of SJM, MGM, Melco Crown or Wynn.

At the industry level, the six casino operators set up the Chamber of Macau Casino Gaming Concessionaires and Sub-concessionaires (Chamber) in 2009. Its priority is to set the ceiling for commissions to 'junket' promoters to limit competition among operators. With regard to responsible gambling, pledges were printed in the 2009 and 2010 pamphlets for Responsible Gambling Awareness Week: "We pledge to provide Responsible Gaming services through the provision of effective Responsible Gaming Programs, information and services." Specifically, the Chamber lists seven kinds of pledge, three of which are to employees, four to casino patrons.

The Chamber's pledge to employees is similar to that of the American 
Gaming Association (AGA, 2003). However, with regard to patrons, the Chamber's pledge is limited to preventing underage gambling, to providing responsible gaming information and information about treatment, and at patrons' requests, to exclude them from gaming promotion mailing lists. The Chamber's pledge to patrons is passive in nature and falls short of the pledges given to patrons by the AGA, and even further in comparison to the codes of conduct in force in Australia, New Zealand and Canada. There is no evidence to show if Macao operators have followed the pledge or not.

Hing (2010) described the evolution of responsible gambling policy and practice among gambling operators in Australia and identified four stages (elementary, engaged, innovative, and integrated stages). From a zero base in 2005, Macao has made some progress along the path towards ensuring responsible gambling, although as Hing (2010) argues, it is still at the elementary stage.

\section{Efforts of counseling service providers and other community groups}

No formal gambling counseling was available across Macao until April 2004 when the Industrial Evangelistic Fellowship (IEF) of Macao initiated such a service. The only governmental gambling counseling service, the Resilience Centre, was set up in 2005. Two other non-governmental gambling counseling services were set up soon after that: the Yat On Centre in October 2006, and the Sheng Kung Hui (SKH) Gambling Counseling Service in 2007.

The Resilience Centre is the largest of the four gambling counseling service providers. All the gambling counselors are Canadian-certified gambling therapists. The Centre provides free helpline and face-to-face counseling, debt and finance counseling, and public awareness and prevention events targeted at high-risk groups. Between 2006 and 2010, 329 problem gamblers and family members had requested help. More than $70 \%$ of cases are considered to have made progress in solving their gambling problems. During this period, centre staff have also offered brief counseling to 1698 gamblers and their family members/relatives via helpline (Resilience Centre, 2007, 2008, 2009, 2010, 2011).

The IEF of Macao is the only organization to offer a 24-hour helpline. It focuses on treatment from a religious perspective and is mainly supported by the IEF of Hong Kong and other donors.

The Yat On Centre offers a hotline and face-to-face counseling. It also organizes responsible gambling workshops for SJM employees. Clients may set total abstinence or controlled gambling as the treatment goal. The centre started an online public education program in 2009, sponsored mainly by IAS. Online outreach via an electronic forum, email, MSN, Facebook and similar means, has been offering help to those who do not actively seek it.

SKH Gambling Counseling is now government-funded, with a team of nine staff. In total, the three NGOs and the Resilience Centre offer counseling to around 300 to 400 problem gamblers and their family members each year, and provide helpline services to about 700 to 1,000 people annually. Data indicate that only 1 to $1.5 \%$ of problem gamblers have sought professional help in Macao, however, a much lower help seeking rate than the $9.1 \%$ noted in a US sample (Cunningham, 2005). 
Many other community groups have also initiated education and public awareness programs for different communities to prevent problem gambling and underage gambling. Such groups include the Macao New Chinese Youth Association, the Young Men's Christian Association of Macau (YMCA), the Youth Volunteers Association of Macao, the Bosco Youth Service Network, the Macao United General Labor Union, and the Macau Gaming Industrial Laborers Association. These community groups represent different communities and promoting responsible gambling is not their main activity. They generally focus their public awareness programs on the communities they represent. For example, the Macao New Chinese Youth Association initiated a series of activities for 'Responsible Gambling Youth Ambassadors' (e.g. workshops, drama, camps, music competitions) to communicate the message to participants that 'life is better without excessive gambling'. Following training, the responsible gambling youth ambassadors are encouraged to distribute information to their peers.

Some programs are jointly organized by several NGOs. For example, 'Rainbow Life' Gaming Industry Employees Service Scheme is jointly organized by the Youth Volunteers Association of Macao, SKH Macao Social Services Coordination Office, and the YMCA. Rainbow Life provides opportunities for casino employees to take part in recreational activities, continuous learning, family activities, and social service activities. The nature of casino employees' shift work has been considered in planning the schedule of these activities. These activities help casino employees lead a healthy and meaningful life and maintain awareness of the risk of excessive gambling. These public education programs did not exist before 2007 but many have been developing very rapidly after obtaining governmental funds. However, their effectiveness has not been evaluated thus far.

\section{Academia's efforts}

Academia plays a vital role in researching and informing policy-makers about the nature, cost, prevention and treatment of excessive gambling in the context of Macao, since many findings in western countries cannot directly be applied in the Chinese cultural environment. For example, the majority of casino patrons in the US, Australia and Canada prefer electronic gaming machines (EGM), while in Macao 90\% of GGR is from Baccarat and less than 5\% is from EGMs (DICJ, 2011). The characteristics of casino patrons in western countries and in Macao are different. Although Macao has a more than 150-year history of legalized gambling, no serious studies on problem gambling or the negative impact of gambling appear to have been undertaken before 2003 ( $\mathrm{Lau}, 2003$ ) .

A literature search identified at least 14 papers in English (Cheung, 2008; Fong et al., 2011; Li et al., 2010; Liu et al., 2009; Tang et al., 2010; Tao et al., 2011; Taormina, 2009; Vong, 2008, 2009, 2010a, 2010b; Wong, 2010; Wong et al., 2008; Wu \& Wong, 2008) and 11 papers in Chinese (Chiang, 2008; Dai, 2007; Huang, 2010c; Huang, 2006; Lau, 2003; Lin, 2004; Man Ian, 2008; So \& Sun, 2007, 2008; Sou \& Cheang, 2008; Zeng, 2005) on problem gambling or responsible gambling in the context of Macao, published between 2008 and 2011. The topics of these papers are mainly on characteristics of problem gamblers, motivations to gamble, risk taking and public policy to reduce the negative impact of gambling. The authors of the majority of 
papers are from three public universities in Macao, that is, the University of Macau, the Macao Polytechnic Institute, and the Institute of Tourism Studies. A detailed review of these papers is beyond the scope of this paper. However, it is evident that to further our understanding about problem gambling and responsible gambling in the context of Macao, more such work needs to be completed.

The public universities in Macao not only focus on teaching and research, but also contribute to the process of public policy-making and assisting the enforcement of public policies, which is possibly unique to Macao. Responsible gambling policy provides a good example of this. Following the 2009 government promise to promote responsible gambling, the University of Macau initiated Responsible Gambling Awareness Week in 2009, together with IAS and DICJ. The program endeavored to educate the public about the concept and of safe ways of gambling responsibly by symposium, posters, pamphlets, and games, among which the symposium also provided a good channel for Macao to learn about international experiences. The Responsible Gambling Awareness Week was held again in 2010 and is expected to be an annual event in the future. Similarly, Macao Polytechnic Institute has begun to assist government to enforce this policy by setting up and maintaining a responsible gambling portal (rg.ipm.edu.mo). The idea behind this is to help gambling consumers to make informed choices by making available 'around the clock' responsible gambling information, such as information about the nature of gambling, the potential risk of excessive gambling, tips for safe gambling, and where to seek help.

\section{Discussion and Conclusion}

Macao government, gambling counseling services and other community groups, casino operators, and academia have made extensive efforts collectively since 2004 to promote responsible gambling, although not utilizing a systematic, planned approach. The Macao government has the key role in developing gaming regulations and policies, and in providing funds for the majority of responsible gambling initiatives. In Macao, no dedicated fund has been set up to support responsible gambling programs and research; instead, general government revenue is used. Casino operators have also made donations. Details of government and casino funding of responsible gaming initiatives are not available to the general public.

The involvement of casino operators is minimal in most of the responsible gaming interventions. Casino operators currently only offer to provide information about problem gambling and where to get help to those who seek it. ATMs are easily accessible within casinos. Accurate information about the chances of winning and losing at casino table games and EGMs is not available to the public. 'Highrollers' are encouraged to get credit from VIP casino rooms. Advertisements whose main content is gambling should be prohibited, according to Section 1 (b) of Article 8 of Law No. 7/89/M (Advertisement Activities). However, tempting gaming advertisements are prolific, especially in the areas of Border Gate and the Outer Harbor Passenger Pier, the routes by which most tourists enter Macao. Many initiatives, such as self-exclusion, pledges, signage and pamphlets seem to be tokenistic, and with the exception of the Responsible Gambling Awareness Week, their effectiveness has not been evaluated. 
There is no unified helpline available currently. The IEF of Macao is the only organization which offers a 24-hour helpline. However, it is understaffed and is not well-funded. In addition, current interventions mainly focus on Macao residents. Tourists, who comprise the majority of gamblers in Macao, are largely ignored. More also needs to be done to prevent potential harms to casino employees. Casino staff have been reported to have a high risk of developing problem gambling (Wu \& Wong, 2008). The employees of casino operators are prohibited from entering their employers' casinos outside work hours. However, they can freely enter casinos run by the five other casino operators.

Usury is ubiquitous on casino floors and it is devastating to problem gamblers. The author's visits to treatment centers and field study around casinos show that it is easy for gamblers to obtain loans from 'loan sharks'. Loan sharks are not allowed to operate in Macao but prosecution is difficult under the current legal system. One of the reasons is that problem gamblers are often desperate to get extra money to keep gambling and they are willing to sign almost any contract without reading it when a loan shark approaches them.

Although extensive efforts have been made to encourage responsible gambling, the prevalence rate of pathological gambling has been increasing, according to surveys conducted in 2003 (Fong \& Ozorio, 2005), 2007 (Fong, 2009) and 2010 (CNStock, 2011). Much more should be done in the future. Based on the stakeholders' perspective, casino operators are not expected to promote responsible gambling actively without pressure from the government and society. Gambling counseling services and other community groups and academia mainly rely on the government for funding. The government has taken the largest role in responsible gambling initiatives, but needs to take more assertive steps to tighten regulations and to set up a dedicated fund for responsible gambling with sound and transparent governance. It is also in the best interest of government and Macao society as a whole, to promote responsible gambling that will help maintain the healthy development of the gaming industry in the long run. The government has promised to promote responsible gambling and regards it as an integral part of gaming policies. With the encouragement of the Central Government of China and in response to increased social concern about the negative impact of the gaming industry, Macao will be able to move forward steadily, to promote responsible gambling under the leadership of local government.

\section{Acknowledgments}

This paper is one of the outputs of an MPI research grant titled "Gamblers' Behavior and Responsible Gambling". I thank Prof Eric Blyth, one anonymous referee, Mr Anthony Leong, and participants of 3rd Asian Pacific Problem Gambling and Addictions Conference held on June 2-3, 2011 in Hong Kong for helpful comments.

\section{References}

AGA. (2003). The American Gaming Association Code of Conduct for Responsible Gaming. Retrieved from http:/ / www.americangaming.org/assets/files/Code_with_bookmarks. pdf

Blaszczynski, A., Collins, P., Fong, D., Ladouceur, R., Nower, L., Shaffer, H. J., ...Venisse, J. L. 
(2011). Responsible gambling: General principles and minimal requirements. Journal of Gambling Studies. Advance online publication.

Blaszczynski, A., Ladouceur, R., \& Shaffer, H. J. (2004). A science-based framework for responsible gambling: The Reno model. Journal of Gambling Studies, 20, 301-317.

Boutin, C., Tremblay, N., \& Ladouceur, R. (2009). Impact of visiting an Onsite Casino information centre on perceptions about randomness and gambling behaviours. Journal of Gambling Studies, 25, 317-30.

Cheung, S. F. (2008). Liberalization of Macao's casino industry and psychological phenomena: An introduction. Journal of Psychology in Chinese Societies, 9, 1-6.

Chiang, W. (2008). Value judgement and public responsibility of the Macau gaming industry. Journal of Macao Studies, 44, 59-64.

CNStock. (2011，May 7). 澳門禁21歲以下人員進入賭場 公職人員禁令不變 [Macau bans people under the age of 21 into the casino; officials' ban remains unchanged] CNStock. Retrieved from http://big5.xinhuanet.com/gate/big5/www.cnstock.com/index/ gdbb/201105/1291960.htm

Cunningham, J. A. (2005). Little use of treatment among problem gamblers. Psychiatric Services, 56, 1024-1025. doi: 10.1176/appi.ps.56.8.1024-a

Dai, A. (2007). A preliminary study on social responsibility of gaming industry in Macao. Journal of Macao Studies, 40, 106-109.

DICJ. (2011). Gross revenue from different game types of games of fortune in 2005-2010. Retrieved from http: / / www.dicj.gov.mo/web/en/information/index.html

Fong, K. C. (2009). Responsible gambling: An approach for Chinese community with legalized casinos. Retrieved from http://www.umac.mo/iscg/Events/RG_symposium/presentations/ HK(1).pdf

Fong, K. C., Fong, H. N., \& Li, S. Z. (2011). The social cost of gambling in Macao: before and after the liberalisation of the gaming industry. International Gambling Studies, 11, 43-56.

Fong, K. C., \& Ozorio, B. (2005). Gambling participation and prevalence estimates of pathological gambling in a Far-East gambling city: Macao. UNLV Gaming Research $\mathcal{E}$ Review Journal, 9, 15-28.

Freeman, E. R. (1984). Strategic management: A stakeholder approach. Boston, MA: Pitman Publishing.

Hing, N. (2001). Changing the odds: A study of corporate social principles and practices in addressing problem gambling. Journal of Business Ethics, 33, 115-144.

Hing, N. (2010). The evolution of responsible gambling policy and practice: Insights for Asia from Australia. Asian Journal of Gambling Issues and Public Health, 1, 19-33.

Ho, E. (2004). Policy address for the fiscal year 2005 of the Macao Special Administrative Region (MSAR) of the People's Republic of China. Retrieved from http://portal.gov.mo/web/ guest/govinfo/policy-address

Ho, E. (2008). Policy address for the fiscal year 2009 of the Macao Special Administrative Region (MSAR) of the People's Republic of China. Retrieved from http://portal.gov.mo/web/ guest/govinfo/policy-address

Huang, G. (2010a). Casino taxation in Macao, Singapore and Las Vegas. Paper presented the 8th European Conference on Gambling Studies and Policy Issues: Crossroads and roundabouts; the right way forward, Vienna, Austria. www.easg.org

Huang, G. H. (2010b). What can Macao learn from Alaska Permanent Fund in managing its fiscal reserve? Macao Journal of Public Administration, 23, 69-79.

Huang, G. (2010c). The problem gambling prevention in Hong Kong, Macao and Mainland China: status quo and prospect. Journal of Macao Polytechnic Institute, 13, 10-18.

Huang, J. (2006). Gambling as an addictive behavior. Journal of Macao Polytechnic Institute, 9, 13-25. 
Ladouceur, R., Jacques, C., Giroux, I., Ferland, F., \& Leblond, J. (2000). Brief communications analysis of a casino's self-exclusion program. Journal of Gambling Studies, 16, 453-460.

Lau, S. (2003). Development of Macao gaming industry and its education strategy. Macao Journal of Public Administration, 16, 103-113.

Li, S., Zhou, K., Sun, Y., Rao, L. L., Zheng, R., \& Liang, Z. Y. (2010). Anticipated regret, risk perception, or both: Which is most likely responsible for our intention to gamble? Journal of Gambling Studies, 26, 105-116. doi: 10.1007/ s10899-009-9149-5

Lin, W. (2004). The psychology of gambling: An initial exploration in the Chinese context. Journal of Macao Polytechnic Institute, 7, 1-12.

Liu, W. P., Lui, S. S., \& Man, D. C. (2009). Individual change schemas, core discussion network, and participation in change: An exploratory study of Macau casino employees. Journal of Hospitality \& Tourism Research, 33, 74-92.

Macao Daily (2011, March 24). 未來三年賭橲總數五千五百張 政府調控博彩業樂觀 [The ceiling of gaming tables is set to 5500 in three years, the government is optimistic to control the development of the gaming industry].

Man Ian, W. K. (2008). On gambling motivation and social guidance in Macao. Journal of Macao Polytechnic Institute, 11, 24-33.

Productivity Commission. (2010). Gambling Productivity Commission Inquiry Report. Melbourne, Australia: Productivity Commission.

Resilience Centre. (2007). Annual Report of 2006. Retrieved from http:/ / www.ias.gov.mo/ $\mathrm{cvf} /$ en/report.jsp

Resilience Centre. (2008). Annual Report of 2007. Retrieved from http://www.ias.gov.mo/ $\mathrm{cvf} /$ en/report.jsp

Resilience Centre. (2009). Annual Report of 2008. Retrieved from http://www.ias.gov.mo/ cvf/en/report.jsp

Resilience Centre. (2010). Annual Report of 2009. Retrieved from http:/ / www.ias.gov.mo/ $\mathrm{cvf} / \mathrm{en} /$ report.jsp

Resilience Centre. (2011). Annual Report of 2010. Retrieved from http:/ /www.ias.gov.mo/ $\mathrm{cvf} / \mathrm{en} /$ report.jsp

Rickwood, D., Blaszczynski, A., Delfabbro, P., Dowling, N., \& Heading, K. (2010). The psychology of gambling, Retrieved from http: / www.psychology.org.au/Assets/Files / APS-Gambling-Paper-2010.pdf

Schwartz, D. G. (2011). Major gaming jurisdictions: ten-year comparison. Las Vegas: Center for Gaming Research, University Libraries, University of Nevada Las Vegas.

Shaffer, H. J., \& Martin, R. (2011). Disordered gambling: Etiology, trajectory, and clinical considerations. Annual Review of Clinical Psychology, 7, 483-510. doi: doi:10.1146/ annurevclinpsy-040510-143928

Siu, R. C. (2006). Evolution of Macao's casino industry from monopoly to oligopoly: Social and economic reconsideration. Journal of Economic Issues, 40, 967-990.

So, M., \& Sun, Y. (2007). Macao residents' gambling behavior and the effects of pathological gambling on families. Journal of Macao Polytechnic Institute, 10, 22-31.

So, M., \& Sun, Y. (2008). A study of risk cognition and gambling behavior among Macao university students. Journal of Macao Polytechnic Institute, 11, 19-33.

Sou, H. T., \& Cheang, S. C. (2008). Problem gamblers in Macao. Journal of Macao Studies, 44, 65-75.

Statistics and Census Service. (2002). Yearbook of statistics 2002. Retrieved from http:/ / www. dsec.gov.mo/Statistic/General/YearbookOfStatistics.aspx?lang=en-US

Statistics and Census Service. (2009). Yearbook of statistics 2009. Retrieved from http:/ / www. dsec.gov.mo/Statistic/General/YearbookOfStatistics.aspx?lang=en-US

Sun, Y., \& Li, S. (2005). Risk perception and gambling behavior among Macau residents: An 
exploratory study. Acta Psychological Sinica, 37, 260-267.

Tang, C. S., Wu, A. M., Tang, J. Y., \& Yan, E. C. (2010). Reliability, validity, and cut scores of the South Oaks Gambling Screen (SOGS) for Chinese. Journal of Gambling Studies, 26, 145-158.

Tao, V. Y., Wu, A. M., Cheung, S. F., \& Tong, K. K. (2011). Development of an Indigenous Inventory GMAB (Gambling Motives, Attitudes and Behaviors) for Chinese gamblers: An exploratory study. Journal of Gambling Studies, 27, 99-113.

Taormina, R. J. (2009). Social and personality correlates of gambling attitudes and behavior among Chinese residents of Macau. Journal of Social and Personal Relationships, 26, 10471071.

Vong, F. C. (2008). Influence of personal factors on Macau residents' gaming impact perceptions. UNLV Gaming Research \& Review Journal, 12, 15-28.

Vong, F. C. (2009). Changes in residents' gambling attitudes and perceived impacts at the fifth anniversary of Macao's gaming deregulation. Journal of Travel Research, 47, 388-397.

Vong, F. C. (2010a). Gambling attitudes and gambling behavior of residents of Macao: The Monte Carlo of the Orient. Journal of Travel Research, 42, 271-278.

Vong, F. C. (2010b). Perception of Macao teachers and students regarding gaming operators' social responsibility. UNLV Gaming Research \& Review Journal, 14, 1-13.

Wong, I. (2010). Internet gambling: A school-based survey among Macau students. Social Behavior and Personality, 38, 365-372.

Wong, V. W., Chan, E. K., Tai, S. P., \& Tao, V. Y. (2008). Problem gambling among university students in Macao. Journal of Psychology in Chinese Societies, 9, 47-66.

Wu, A. M., \& Wong, E. M. (2008). Disordered gambling among Chinese casino employees. Journal of Gambling Studies, 24, 207-217. doi: 10.1007/ s10899-007-9068-2

Zeng, Z. (2005). Bounded-rationality of gambling-A study of causes of gambling behavior. Journal of Macao Polytechnic Institute, 8, 1-11.

Zeng, Z. (2010). Status quo and future of casinos around the World. Beijing, China: Chinese Economy Publishing House. 